\title{
Teaching Behaviour and Approximate Analysis of Structural Systems
}

\author{
Philippe Duffour, Andrew Foster \\ Civil Engineering \\ University College London, London, UK \\ Contact: p.duffour@ucl.ac.uk
}

\begin{abstract}
A new and innovative master's level course has been developed at University College London (UCL) offering a systematic grounding in the behaviour of structural systems. Students are taught how to tackle complicated structural problems using a combination of simpler structural subsystems. In so doing, students are encouraged to examine the underlying physics of the problems and how this might influence the overall structural form and composition of structural systems. To enable confident and intuitive decision making, structural systems are first presented in qualitative terms. Once essential decisions on the composition of the structural system have been made, students are then shown how to provide initial estimates of element sizes and cost comparisons through approximate structural analysis techniques. Furthermore, students are then made aware of how these methods can be used at later project stages to judge the accuracy of solutions to more detailed, computer-aided approaches. The course is organised around a set of structural subsystems. Each is taught in terms of their behaviour, application, methods of approximate analysis, and preliminary design procedures.
\end{abstract}

Keywords: Structures Teaching, Structural Systems, Structural Behaviour, Approximate Analysis

\section{Introduction}

The proliferation of advanced computer-aided design technologies such as the finite element method has led to a fundamental questioning of the relevance of much of conventional teaching in structural mechanics. Much is being debated about what 'fundamentals' ought to be taught and what place should commercial finite element (FE) packages hold in this teaching. Some, mostly on the academic side argue that traditional hand calculation methods still have their place in teaching the basic concepts of structural mechanics and structural behaviour. On the other hand a growing number of people, often at the commercial end of the profession, claim that structural engineering is now much more about the efficient and robust management of a string computer modelling processes and that too much emphasis on the physics of structural mechanics is an unhelpful distraction. Computer modelling tools are also fundamentally redefining the relationship between architects and structural engineers to an extent that is still largely unknown.
Whatever the answer to these questions is, it seems fairly clear that 'business as usual' in teaching structural mechanics will not do for much longer so the time is ripe for experimenting. At University College London (UCL), we have decided to develop a new course module called 'preliminary design and approximate analysis of structural systems'. This module will furnish UCL graduates with an intuitive understanding of structural behaviour, placing them in a position to confidently make key structural decisions and to rapidly assess the dependability of the results from intricate computer models.

\section{Motivations and course objectives}

Finite element packages have been great enablers for the structural engineering profession. However it is also arguable that they limit the structural engineer's contribution at the conceptual design phase due to the significant investment in time necessary for their implementation. Having the ability to perform approximate analyses of more complex structural systems with little or no computer assistance enables structural engineers 
to make more informed and valuable contributions much sooner in a project's life-cycle, as well as providing better integration between the wishes of the client, architects, and other building systems engineers. Structures courses for architects are usually structured around structural systems with a strong emphasis on qualitative behaviour. The intention was to bring this awareness and understanding to civil engineering students who too often only see structures as a disparate collection of elements to be sized. Therefore the objectives of the course were (1) to bring this awareness of existing systems and (2) to provide students with tools to analysis approximately these structural systems. With (2), the intention was first to bring out the main features structural behaviour in each system, second to give some grounding for preliminary sizing of each system and third to provide students with tools to check computer output at a later stage in the design process.

\section{Module content and delivery}

There is no perfect way of categorising structural systems. Whatever one choses, there are always overlaps and misfits. From a structural engineering point of view, structures are often classed by material, associated with a particular code: e.g. EC2 for reinforced concrete, EC3 for steel. Instead we opted for the categories that architects tend to follow: arches, cables, trusses, posts-and-beams, moment-resisting frames, bridges, tall building systems, shells and tensile structures. The course was broadly split in two: systems in the first half (up to bridges) can be well described as twodimensional, whereas in the second half, the systems were intrinsically three-dimensional.

The module was delivered over a term (10 weeks) at four hours per week. Each system was covered over a week with two hours of lectures first, followed by two hours of tutorial or design workshops. Shells and tents to which students are rarely exposed as standard were allocated more time to provide a deeper theoretical grounding.

The course is assessed by $60 \%$ of coursework and $40 \%$ of exam. The coursework was made of three assignments. The first one was a poster presentation on an existing structure chosen from a list in London. This followed a walking tour of
London landmark buildings that took place early in the course. The students were taken from UCL to the City via King's Cross, Saint Pancras, and Farringdon. The second assignment was to produce the preliminary design of a tall building. For the third coursework assignment, the students had to produce a preliminary design of a semi-permanent 'covering structure' for Somerset House. The two design assignments were co-developed with designers from AKTII who also contribute to the marking. The bridge sessions were co-developed and delivered by Cowi (formerly Flint and Neill) so the course had significant input from industry and these relationships will be further developed as the course evolves over the next few years.

\section{Reflections and the future}

The course was offered as a master's option for the first time this year. It attracted 30 students. Even though the first systems (arches, cables, trusses) are often be treated in early undergraduate years, this course shed a new light on them. For example, in the case of cables emphasis was given to the importance of choosing an appropriate span-to-sag ratio, understanding the effects of having banks at different levels, and the influence of cable stretching on internal tension. There is no single book that covers what this course is trying to achieve. Schodek's Structures [1] is probably the closest but it remains fairly elementary. Hence, each structural sub-system became a research project in its own right and it was not always easy to decide how much theoretical background to cover. In future, the course will have a greater thematic emphasis, shifting between say tall buildings and large-span structures on a yearly basis.

\section{References}

[1] Schodek D. and Bechthold M. Structures ( $7^{\text {th }}$ Edition). London: Pearson; 2014. 